Published as: Griffiths, M.D. (2011). Gaming convergence: Further legal issues and psychosocial impact. Gaming Law Review and Economics, 14, 461-464.

Social gambling via Facebook: Further observations and concerns

\author{
Dr Mark D. Griffiths \\ Professor of Gambling Studies \\ International Gaming Research Unit \\ School of Social Sciences \\ Nottingham Trent University \\ Burton Street \\ Nottingham \\ NG1 4BU \\ United Kingdom
}

Disclaimers and Competing Interests: The author did not receive any funding for this article. The author has received funding for a number of research projects from the Gambling Commission of Great Britain and the UK Responsible Gambling Fund. The author also undertakes consultancy for various gaming companies in the area of social responsibility in gambling. 


\section{Social gambling via Facebook: Further observations and concerns}

The editorial by Schneider ${ }^{1}$ in a recent issue of Gambling Law Review and Economics raised a number of interesting observations in relation to gambling via social networking sites such as Facebook. The launch of the first gambling for money game (i.e., Bingo Friendry) on Facebook received lots of media interest, and most gaming operators are now watching closely to see whether the move from social gaming to social gambling will be profitable. This article briefly examines some further observations and concerns in relation to social gambling via Facebook and other social networking sites.

In the UK, there are 31 million registered users of Facebook who are over 18 years of age . $^{2}$ According to a recent study by Experian Hitwise, UK visitors have an average Facebook session time of 22 minutes $^{2}$. The study also revealed that a quarter of those visiting Facebook visit and entertainment website such as games and music, immediately after leaving the website. This shows gambling companies that there is a good market size to access and that users could be quite receptive to gambling on the site. Social networking sites are profitable, and Facebook currently takes 30\% income generated from payments in games such as Farmville and Zynga Poker ${ }^{3}$. Furthermore, in June 2012, Facebook reported that $£ 123$ million of the $£, 760$ million of total revenue was attributed to social gaming ${ }^{3}$. Gambling-type games are popular on Facebook, and the November 2012 monthly figures for the most popular games played on Facebook showed that Texas Hold 'Em Poker was the second most popular game behind FarmVille 2 with 34 million players worldwide 3 .

As Schneider's ${ }^{1}$ article noted, there is no accepted definition of what social gaming actually is, and as I noted in a previous article in this journal ${ }^{4}$, the lines are beginning to blur between social gaming and gambling. Online gambling operators and software developers (e.g., Bwin, Party Gaming, PlayTech, etc.) are positioning themselves for entry into the social gaming market, and vice-versa (e.g., Zynga). These new types of social gaming and gambling-like experiences that people of all ages are now being exposed to raises various moral, ethical, legal and social issues.

There are clear drivers as to why gambling via social networking sites has become inevitable. As evidenced in other remote gambling media such as the internet and mobile phone, there is clearly a desire to gamble among a section of most communities. Other reasons include (i) growing disposable income, (ii) the convenience, availability, and 
usability of social networking sites, (iii) continued technology improvement and increased broadband speeds, and (iv) increasing social network user penetration. The constraints (which I believe will all be overcome in time) include (i) regulatory issues (as different jurisdictions have different laws or next to no laws at all relating to social gambling), (ii) the sometime poor age verification protocols of social networking sites, (iii) the lack of user confidence concerning social networking sites among some demographic groups, and (iv) trust issues around payment processing on social networking sites.

Technology hardware is becoming increasingly convergent and there is increasing multimedia integration ${ }^{5}$, and people of all ages are spending more time interacting with technology (Internet, video games, interactive television, mobile phones, MP3 players, etc. $)^{4}$. Such convergent content includes (i) gambling including video game elements, (ii) video games including gambling elements, (iii) gambling and gaming via social media, (iv) online penny auctions that have gambling elements, and (v) television programming with gambling-like elements ${ }^{4-8}$.

With specific reference to the social media, many social games played on social networking sites have gambling-like elements - even if no money is involved ${ }^{6}$. Social networking games provide pleasure, accomplishment and friendship ${ }^{7}$. Even when games do not involve money (e.g., playing poker for points on Facebook), it introduces players (e.g., youth) to the principles and excitement of gambling. ${ }^{8}$. Companies like Zynga have been accused of leveraging the mechanics of gambling to build their gaming empire ${ }^{7}$. One of the key psychological ingredients in both gambling (e.g., slot machine) and social gaming is the use of operant conditioning and random reinforcement schedules ${ }^{8}$. Getting rewards every time someone gambles or plays a game leads to people becoming bored quickly. Therefore, small unpredictable rewards leads to highly engaged and repetitive behavior for those players. In a minority of cases, this may lead to addiction ${ }^{8}$. Both gambling operators and social gaming developers use intermittent and unpredictable rewards to facilitate habitual behavior (i.e., get repeat custom).

The psychosocial impact of this new leisure activity is only just beginning to be investigated by those in the gaming field. Social networking sites have the potential to normalise gambling behavior as part of the consumption patterns of a non-gambling leisure activity ${ }^{8}$. This may change social understandings of the role of gambling among 
young people ${ }^{8}$. A 2011 national gambling survey of British adolescents ( $\mathrm{n}=2739$; aged 1116 years) by Ipsos MORI reported that around one in seven children $(15 \%)$ played free or practice gambling games in the past week, and that the most popular form of practice gaming was through Facebook. One in ten children (11\%) said they had played free games on social networking website Facebook. The report noted:

"There may be some value in tackling children's access to free online trial games. There is a clear link between playing free trial games on the internet and gambling for real money (online and offline). However, regulators will need to target a range of games and websites to monitor this effectively, as children report playing games on a wide variety of websites."

In these situations, there is no money changing hands but it raises questions about whether gambling with virtual money encourages positive attitudes towards gambling in people (e.g., young people particularly). For instance, does gambling with virtual money lead to an increased prevalence of actual gambling? Using statistical modeling, research carried out by Forrest, McHale and Parke ${ }^{10}$ using data from the 2009 British adolescent gambling study ( $\mathrm{n}=8958$; aged 11-16 years) reported that gambling in money-free mode (games that are widespread on Facebook and other social networking sites) was the single most important predictor of whether the child had gambled for money, and one of the most important predictors of children's problem gambling. (However, it should be noted that this relationship was correlational and not causal). Today's youth are more techsavvy, have no techno-phobia, and very trusting of these new technologies ${ }^{11}$. Many of these young people, their first gambling experiences may come not in a traditional offline environment but via the internet and social networking sites, mobile phone or interactive television ${ }^{8}$.

I have previously argued ${ }^{7}$ that introduction of in-game virtual goods and accessories (that people willingly pay real money for) was a "psychological masterstroke". In this sense, it becomes more akin to gambling, as social gamers know that they are spending money as they play with little or no financial return. They are buying entertainment and the intrinsic play of the game itself is highly psychologically rewarding. Like slots players, social network gamers love the playing of the game itself and money is the price of entry that they are willing to pay. Unlike those involved in social gaming, gamblers do at least have an outside chance of getting some of the money they have staked back. Therefore, allowing those who play social games the chance to actually get their money back (or gain 
more than they have staked) is why companies currently operating social games want to get into the pure gambling market.

In the popular press, Nicole Lazzaro has claimed there are four elemental keys that determine game success ${ }^{3}$. These are (i) hard fun (i.e., overcoming difficult obstacles to progress in the game in pursuit of winning); (ii) easy fun (i.e., enjoying the game even if they don't win); (iii) altered states (i.e., playing because it makes players feel good psychologically and changes their mood for the better); and (iv) the people factor (i.e., socially interacting with other players). She also says that the most successful games will engage players' curiosity, allow players to socialize with friends, challenge players to overcome obstacles to achieve goals and relate to people's lives in a meaningful way.

There are clearly issues that need to be clarified and addressed. Castillo ${ }^{12}$ recently asserted that:

The first and most pressing concern is that related to the legal and regulatory framework... There is an issue for those Facebook members that do not sign up with the correct details and perhaps claim an erroneous age... Online bingo rooms offer chat forums alongside the bingo room in order to cater for the inherently social element of the game. Facebook offers the same functionality, together with the world's largest online community... Other products that are well suited to the Facebook platform are casino games such as blackjack and slots, as these games are quite fast to play and could represent a 'break.' from the normal Facebook activities, without leaving the website.

A recent article by Shortt ${ }^{13}$ claimed there are three potential target audiences for gambling via social networking sites - the typical social gamer, the typical gambler, and the new category of social gambler (i.e., somebody for whom the freemium model is not compelling, but doesn't hold accounts with gambling or casino operators).

Facebook has changed the way people (and possibly) gamblers are playing games. Empirically, we know almost nothing about the psychosocial impact of gambling via social networking sites although research suggests the playing of free games among adolescents is one of the risk factors for both the uptake of real gambling and problem gambling. Whatever research is done, we can always be sure that the gaming industry will be two steps ahead of both researchers and legislators.

\section{References}


(1) Schneider, S., Social gaming and online gambling. 16 GAMING LAW REVIEW ECONOMICS, 711-712 (2012).

(2) Castillo, M., Real money gaming on Facebook. I-GAMING BUSINESS AFFILIATE, October/November, 31 (2012).

(3) Griffiths, M.D., "Social Gaming and Convergence with Gambling." Paper presented at the Social Gaming Expert Seminar, Gambling Commission, Birmingham, UK (December 2012).

(4) Griffiths, M.D., Gaming convergence: Further legal issues and psychosocial impact. 15 GAMING LAW REVIEW ECONOMICS, 461-464 (2011).

(5) King, D.L., Delfabbro, P.H. \& Griffiths, M.D., The Convergence of Gambling and Digital Media: Implications for Gambling in Young People, 26 JOURNAL OF GAMBLING STUDIES, 175-187 (2010).

(6) Griffiths, M.D., Gaming in Social Networking Sites: A Growing Concern? 9(5) WORLD ONLINE GAMBLING LAW REPORT, 12-13 (2010).

(7) Griffiths, M.D. (2012). Gambling on Facebook? A cause for concern? 11(9) WORLD ONLINE GAMBLING LAW REPORT, 10-11 (2012).

(8) Griffiths, M.D. \& Parke, J. (2010). Adolescent gambling on the Internet: A review. 22 INTERNATIONAL JOURNAL OF ADOLESCENT MEDICINE AND HEALTH, 59-75 (2010).

(9) Ipsos MORI, Underage Gambling in England and Wales: A research study among 11-16 year olds on behalf of the National Lottery Commission. London: Author (2011).

(10) Forrest, D. K, McHale, I \& Parke, J., Appendix 5: Full report of statistical regression analysis. In Ipsos MORI, BRITISH SURVEY OF CHILDREN, THE NATIONAL LOTTERY AND GAMBLING 2008-09: REPORT OF A QUANTITATIVE SURVEY. London: National Lottery Commission (2009).

(11) Griffiths, M.D., 7 Technological trends and the psychosocial impact on gambling. CASINO AND GAMING INTERNATIONAL, 77-80 (2011).

(12) Michael Castillo (2012). Real money gaming on Facebook. I-GAMING BUSINESS AFFILIATE, October/November, 31.

(13) Shortt, A., It's social but not as we know it. I-GAMING BUSINESS AFFILIATE, October/November, 59-61 (2012). 